\title{
Projetos de formação de cursos técnicos de nível médio em saúde: análise crítica
}

\section{Formación de técnicos de nivel medio en salud: análisis crítico de los planes del curso}

\author{
Adriana Katia CORRÊA ${ }^{1}$ \\ Maria José CLAPIS²
}

\begin{abstract}
Resumo
É significativa a atuação dos trabalhadores técnicos no cuidado em saúde. O objetivo deste estudo é analisar quais são os objetivos, finalidades e concepçôes adotados nos planos de cursos de educação profissional técnica de nível médio na área da saúde, de escolas públicas e privadas no estado de São Paulo. Pesquisa qualitativa, documental, fundamentada em perspectiva histórico-dialética. Os objetivos e concepçóes adotados trazem à tona a tensão entre formação humana e formação para o mercado e suas implicaçóes em termos de afastamentos e aproximaçóes em relação ao SUS.
\end{abstract}

Palavras-chave: Educação profissional. Formação profissional. Políticas públicas em educaçáo.
Resumen

Es significativa la actuación de los trabajadores técnicos en el cuidado en salud. El objetivo de este estudio es analizar cuales son las finalidades/objetivos y las concepciones adoptadas en los planos de cursos técnicos de nivel medio del área de la salud, de escuelas públicas y privadas que ofertan educación profesional técnica de nivel medio en el estado de São Paulo. Investigación cualitativa, documental, fundamentada en perspectiva histórico-dialéctica. Los objetivos y concepciones adoptados traen a tono la tensión entre formación humana y formación para el mercado y sus implicaciones en términos de distanciamientos y aproximaciones a la formación para el Sistema Unico de Salud.

Palabras Clave: Educación profesional. Formación profesional. Políticas públicas en educación.

1 Professora Associada da Escola de Enfermagem de Ribeirão Preto da Universidade de São Paulo (EERP/ USP). Doutora em Enfermagem pela USP e Pós-Doutorado pela Faculdade de Educaçáo da UNICAMP - SP. Lattes: http://lattes.cnpq.br/8359047427445402; ORCID: https://orcid.org/0000-0003-1496-6108. E-mail: adricor@eerp.usp.br

2 Professora Sênior da EERP/USP. Doutora em Enfermagem pela Universidade de São Paulo. Lattes: http://lattes.cnpq.br/1846996596566833; ORCID: https://orcid.org/0000-0002-2896-3808. E-mail: maclapis@eerp.usp.br 


\section{Introdução}

O trabalho em saúde, que historicamente se configura como coletivo, vem incorporando trabalhadores formados no nível superior de ensino e trabalhadores técnicos de nível médio. Em relação aos postos de trabalho, os níveis técnico e elementar, juntos, perfazem 52,2\% (MOROSINI et al., 2013). Esse percentual expressa o quanto é significativa a atuação dos trabalhadores (níveis técnico e elementar) no cuidado em saúde, no âmbito do Sistema Único de Saúde (SUS), o que se relaciona, dentre outros aspectos, à sua formação.

Uma característica marcante na história da educação profissional no Brasil refere-se à dualidade que reproduz a própria estrutura social: para as elites, o ensino propedêutico e, para os trabalhadores, o ensino profissional. Nessa dualidade, a formação geral que alicerçaria a inserção crítica na sociedade está reduzida ou quase abolida no denominado "ensino profissional" (MOURA, 2010; ROMANELLI, 2012; CAIRES; OLIVEIRA, 2016).

Ao longo de diversos períodos históricos, essa característica - com alguns recuos e avanços - vai instituindo a separação entre trabalho manual e intelectual, sendo o primeiro relacionado a condiçóes fragilizadas dos processos formativos, que vão desde práticas de ensino informais até aquelas aligeiradas e centradas no âmbito estritamente técnico, o que será marcante na organização da educação profissional técnica de nível médio, na área da saúde.

Estudos já desenvolvidos (RAMOS, 2009; PRONKO, 2011; GALVÃO; SOUSA, 2012) explicitam a presença, em escolas técnicas da área da saúde, incluindo algumas Escolas Técnicas do SUS (ETSUS) de concepçóes que aproximam a formação mais da lógica do mercado, instrumental, com limites à formação emancipadora, mais coerente à perspectiva de uma formação que contribua para a sustentação de um modelo assistencial voltado às necessidades de saúde da população brasileira e ao SUS.

Quais são os objetivos, finalidades e principais concepçóes que vêm norteando os projetos de formaçáo dos cursos técnicos de nível médio na área da saúde, no estado de São Paulo? Estão relacionados a quais projetos de educação, saúde e sociedade?

O objetivo deste estudo é analisar quais são os objetivos, finalidades e concepções adotados nos planos de cursos de educação profissional técnica de nível médio na área da saúde, de escolas públicas e privadas no estado de São Paulo. 


\section{As políticas de educação profissional no Brasil e interfaces com a área da saúde a partir dos anos 1990: algumas aproximações}

Os anos 1990, no Brasil, demarcaram mudanças substanciais em termos econômicos e políticos que já vinham se estruturando em outros países, trazendo um cenário que propiciava o encolhimento do Estado em relação às políticas sociais e um avanço na direção do capital, por meio de um modelo marcado por mudanças na forma de investimentos, com ênfase no capital financeiro e na organização do trabalho (reestruturação produtiva), com incorporação de avanços tecnológicos, como a microeletrônica e a robótica, além de alteraçóes nas formas de gestáo, em processo de fortalecimento de reprodução do capital (FRIGOTTO, 2010; OLIVEIRA, 2013).

A década de 1990 e parte dos anos 2000 foram marcadas por embates políticos entre projetos de educação e sociedade - conservadores e progressistas - que repercutiram nos rumos da educação profissional técnica de nível médio (MOURA, 2010; MOURA, 2013), a partir da promulgação da Lei de Diretrizes e Bases da Educação Nacional (LDB) no 9394/96 (BRASIL, 1996), que propiciou a atuação da iniciativa privada em todos os níveis de ensino, e de significativa legislação complementar: o Decreto no 2208/97 (BRASIL, 1997) que marca a separação entre ensino médio e formação profissional, revertido pelo Decreto n ${ }^{\circ}$ 5154/2004 (BRASIL, 2004); e a Resolução CNE/CEB no 06/2012 para a Educação Profissional Técnica de Nível Médio (BRASIL, 2012), que substituiu a Resolução CNE/CB no 04/99 (BRASIL, 1999) (essa última fundamentada no Decreto no 2.208/97).

Cabe apontar que as atuais propostas para o ensino médio, regulamentadas pela Lei no 13.415/2017 (que também abordam a educação profissional técnica de nível médio) estão significativamente atreladas aos ditames neoliberais, o que implica em perversos limites na formação, coerentes à manutenção das desigualdades sociais (KUENZER, 2017; RAMOS, 2017).

Moura e Lima Filho (2017) ponderam que a lei em questáo pertence a uma racionalidade maior composta por medidas que têm por intenção reconfigurar o Estado brasileiro na direção de torná-lo ainda "mais mínimo" quanto às garantias dos direitos sociais e "mais máximo" para regular os interesses do grande capital nacional e internacional, demarcando-se, assim, um processo de radicalização do neoliberalismo. Essa legislação acaba por fragmentar o ensino médio em diversos itinerários, bem como por atacar a concepção de ensino médio como etapa final da Educação Básica, o que significa afrontar "a LDB e os princípios constitucionais do direito subjetivo à educação e da universalização da Educação Básica” (MOURA; LIMA FILHO, 2017, p. 121). 
$\mathrm{Na}$ mesma perspectiva, a partir das mudanças nas legislaçóes do ensino médio, incluindo a Base Nacional Comum Curricular - Educação Básica - temse o Parecer CNE/CP no 17/2020 que sustenta a proposição de novas Diretrizes Curriculares Nacionais Gerais para a Educação Profissional e Tecnológica. Esse dispositivo busca

(...) atender adequadamente às mudanças que pretendem ser implementadas na educaçáo brasileira, exigidas para dar a devida atenção às demandas atuais do mundo do trabalho em constante evolução. (BRASIL, 2020, p. 4)

Apesar da área da saúde deparar-se com a necessidade de transformaçôes na formação dos trabalhadores para responder às demandas desencadeadas pelas lutas político-sociais a favor da saúde como direito, desde o fim da década de 1970, dado o contexto político-econômico atual, emergem desafios políticos na manutenção da luta pelo SUS e por uma nova sociedade, em contraposição às políticas privatizantes cada vez mais fortalecidas, em âmbito internacional e nacional.

A esse respeito, Campos et al. (2016, p. 261) descrevem que:

(...) a abertura ao capital estrangeiro para investimento em saúde no Brasil, pela lei 13.097/20156, a presença de seguradoras transnacionais de saúde no mercado brasileiro, a privatização dos serviços do SUS, e as propostas para a obrigatoriedade da disponibilizaçáo de seguros-saúde pelos empregadores, pelo Projeto de Emenda Constitucional 4517, confirmam esse cenário sombrio, além do fato do progressivo desfinanciamento do SUS.

No campo da saúde, dado o momento histórico contemporâneo, é marcante o fortalecimento do capital e do mercado, em prejuízo do interesse público. Estruturalmente, o capitalismo se encontra em fase de dominância financeira e, nas últimas duas décadas, o interesse do capital em captar maiores recursos socialmente produzidos fere o regime político previsto pela Constituição de 1988. Se, de um lado, podem ser destacados avanços a partir do reconhecimento constitucional do direito à saúde, por outro lado, a garantia plena desse direito ainda não foi alcançada, tendo em vista o cenário de disputas entre "o projeto democrático-popular do Movimento da Reforma Sanitária Brasileira e o projeto liberal-conservador ao qual se vincula o setor privado na saúde”. Nessa perspectiva, segue como desafio a luta pelo direito à saúde inserida na luta mais ampla pela democracia (SOUZA et al., 2019, p. 2785). 
Cabe destacar ainda - na especificidade da área da saúde, e no que se refere à educação profissional técnica de nível médio - que a participação do setor privado no oferecimento de matrículas na formação técnica é expressiva. Dentre os 10 cursos com maior número de matrículas, na rede privada, em primeiro lugar está o técnico de enfermagem, com 121.357 matrículas (17,6\%), seguido por Segurança do Trabalho, com 89.059 matrículas (12,9\%). Na rede pública, o curso de enfermagem ocupa a quinta posiçáo, com 32.475 matrículas (4,3\%). O curso com maior número de matrículas na rede pública é o de informática com 92.398 matrículas (12,3\%) (BRASIL, 2014a).

No campo da saúde, de um lado fica demarcada a educação profissional técnica de nível médio (EPTNM) inserida, predominantemente, no setor privado, e submetida a ditames político-legais significativamente coerentes à lógica neoliberal e, por outro, a EPTNM como perspectiva de compor a luta pelo direito à saúde, pela consolidação do SUS, a partir dos preceitos da Reforma Sanitária, e de melhores condiçóes de vida para a população brasileira.

\section{Metodologia}

Este estudo se insere em projeto de pesquisa sobre a formação dos trabalhadores técnicos da área da saúde no estado de São Paulo ${ }^{3}$. Caracteriza-se como pesquisa qualitativa, na perspectiva histórico-dialética, cujos dados serão acessados por meio de análise documental (GHEDIN; FRANCO, 2011; CELLARD, 2012).

Considerando a diversidade das instituiçóes que oferecem cursos técnicos na área da saúde, no estado de São Paulo, foram envolvidas seis escolas mantidas sob diferentes entidades administrativas, levando-se em conta também o seguinte critério: que nos últimos cinco anos tenham oferecido pelo menos um dos cursos que, segundo pesquisa anteriormente desenvolvida pelas autoras ${ }^{4}$, sejam aqueles mais ofertados e com maior número de matrículas no estado, ou seja, enfermagem, radiologia, farmácia e/ou nutrição. ${ }^{5}$

3 Formação de trabalhadores técnicos de nível médio em saúde no estado de São Paulo: problemáticas e desafios no contexto do SUS - Projeto de pesquisa Regular com financiamento FAPESP - Processo ${ }^{\circ}$ 2019/06374-6.

4 "Formação de trabalhadores técnicos em saúde no Brasil: relatório do Estado de São Paulo", 2018, 181 p. - inserido em Projeto Multicêntrico "Formação de Trabalhadores Técnicos em Saúde na Região das Américas", coordenado pela Escola Politécnica de Saúde Joaquim Venâncio/FIOCRUZ-RJ (Centro Colaborador da OMS para a educação de técnicos na saúde), do qual participaram, institucionalmente, como representantes de uma universidade pública, as autoras deste artigo.

5 Cabe destacar que, seja na oferta de cursos ou no número de matrículas, estética é o curso que ocupa a terceira posição segundo dados de pesquisa anterior. Todavia, não entrará no critério de inclusão adotado, 
Posto que a maior parte das instituições públicas que oferecem esses cursos são estaduais, participaram deste estudo duas ETECs - Centro Paula Souza do interior, marcante instituição na oferta desses cursos no estado. As Escolas Técnicas do SUS (ETSUS) representam um número bem menor de instituições, muito embora seja relevante a história dos Centros Formadores e da proposta de constituição da rede de Escolas Técnicas do SUS. Dadas as peculiaridades significativas para alavancar o novo modelo assistencial no país e no estado, também foram incluídas duas delas para a presente pesquisa: uma da capital e outra do interior.

Quanto às instituiçóes privadas, foram envolvidas uma representante do sistema "S" - SENAC - do interior, tendo em vista a presença ampla do Sistema "S" no estado de São Paulo desde os primórdios na década de 1940, e outra escola privada particular do interior que faz parte do grupo das instituiçóes que mais ofertam cursos técnicos da área da saúde no estado de São Paulo.

Vale destacar no que se refere ao interior que, além do critério já mencionado, foram escolhidos municípios que integram parte de uma das Redes Regionais de Atençáo à Saúde. Portanto, a pesquisa proposta poderá explorar, trazer informaçóes e análises de escolas/cursos técnicos que estáo formando trabalhadores técnicos da área da saúde para uma regiáo específica, o que poderá ter desdobramentos posteriores quando da divulgação dos dados.

Após a aprovação deste projeto no Comitê de Ética em Pesquisa da EERP- USP, com Parecer no 4.169.926, atendendo à Resolução no 510/2016/CNS (BRASIL, 2016), foi feito contato, por e-mails, com Diretores(as) e/ou coordenadores(as) de cursos para solicitação de acesso à última versão do plano dos cursos que atendiam ao critério adotado. Além disso, algumas instituiçôes também forneceram, para consulta, o plano de gestão ou regimento institucional, de maneira a viabilizar dados que favorecessem o entendimento acerca do projeto de curso em análise e de seu contexto. Esses outros documentos foram complementares na análise. Assim, foram analisados nove planos de cursos, envolvendo cinco áreas profissionais, tendo em vista que, em algumas instituições, o plano de dado curso é o mesmo para as distintas unidades. Para manter o sigilo, as instituiçóes foram denominadas com a sigla ET (Escola Técnica) seguida de números de acordo com a sequência de análise (ET1 a ET6).

porque a opção é pela análise de cursos que estejam mais diretamente associados ao cuidado em serviços de saúde/comunidade. Em se tratando da Rede de Escolas Técnicas do SUS, específicas da área da saúde e com missão voltada diretamente à formação para o SUS - tendo em vista peculiaridades do atual momento político dessa Rede que tem implicado em menor oferta de alguns cursos, dentre eles os mais ofertados e com matrícula no estado - foram também incluídos outros cursos. Assim, no cômputo geral, foram analisados documentos dos seguintes cursos: enfermagem, nutriçāo e dietética, farmácia, saúde bucal e citopatologia. Ainda não obtido acesso à escola que oferta radiologia. 
Foi utilizado um roteiro norteador para a busca de dados nos documentos disponibilizados, com foco: nas finalidades/objetivos institucionais do curso; nas concepçóes relacionadas ao campo de saber da saúde, com ênfase na aderência ou não à formação para o SUS e; nas concepções relacionadas ao campo de saber da educação, ou seja, nortes teóricos fundamentais relacionados à proposta pedagógica do(s) curso(s) analisado(s).

$\mathrm{Na}$ sequência, foram empreendidas: atentas e repetidas leituras de cada documento completo; sínteses de cada um, a partir do roteiro norteador e; articulaçóes entre as sínteses, delineando-se uma análise que englobasse o conjunto dos cursos técnicos da área da saúde envolvidos de todas as escolas que compóem este estudo. Tendo em vista a amplitude e a complexidade dos documentos em relação às concepçóes do campo da saúde, fez-se a opção de explicitar a aproximação ou não à formação para o SUS. No campo educacional, o predomínio do referencial das competências - assumido por todos os cursos e que por sua vez tem relaçóes com outras concepçóes adotadas - implica diretamente na formação do trabalhador técnico da área da saúde, razão pela qual optou-se por centrar o olhar em alguns aspectos desse referencial.

Considerando a perspectiva histórico-dialética, destaca-se que para que o pensamento

possa progredir do abstrato ao concreto, tem de mover-se no seu próprio elemento, isto é, no plano abstrato, que é negação da imediaticidade, da evidência e da concreticidade sensível. A ascensão do abstrato ao concreto é um movimento para o qual todo início é abstrato e cuja dialética consiste na superação desta abstratividade (...) Isso implica movimento da parte para o todo e do todo para a parte; (...) da totalidade para a contradição e da contradição para a totalidade (...) O processo de pensamento não se limita a transformar o todo caótico das representaçóes no todo transparente dos conceitos; no curso do processo o próprio todo é concomitantemente delineado, determinado e compreendido. (KOSIC, 1976, p. 30)

\section{Resultados: em foco os projetos de cursos técnicos da área da saúde}

Os planos de cursos analisados apresentam concepçóes construídas a partir de documentos como: a LDB no 9394/96 (BRASIL, 1996); as Diretrizes Curriculares Nacionais para a Educação Profissional Técnica de Nível Médio, tanto as da década de 1990 (BRASIL, 1999) como as dos anos 2000 (BRASIL, 
2012); os Catálogos Nacionais dos Cursos Técnicos (BRASIL, 2012; BRASIL, 2014b) e; a Classificação Brasileira de Ocupaçóes - CBO (2002). Além desses mencionados por alguns documentos, apreende-se também a utilização dos Referenciais Curriculares da Educação Profissional de Nível Técnico (BRASIL, 2000).

Dentre os objetivos específicos, podem ser mencionados alguns que se referem à formação voltada para a cidadania e que envolvem também a ciência, a tecnologia, a ética, bem como o desenvolvimento intelectual crítico:

Possibilitar o desenvolvimento de competências que permitam ao aluno exercer a sua cidadania ativa, de forma solidária, no exercício das funçóes de técnico (ET1; ET2); Levar o futuro profissional a colocar em suas açôes a ciência, a tecnologia e a ética a serviço da vida (ET1; ET2);

Formar profissionais de saúde cientes dos direitos e deveres dos cidadãos (...) (ET3);

O Curso Técnico (...) visa o aperfeiçoamento na concepção de uma formação técnica que articule trabalho, cultura, ciência e tecnologia como princípios que sintetizem todo o processo formativo (...). Levar o educando a um aprimoramento como pessoa através de uma formação ética e um desenvolvimento intelectual crítico (ET6).

Em outros planos, ao longo do documento também é feita referência à formação para a cidadania:

Em cada conteúdo, deve-se trabalhar o conhecimento do aluno, sobre a compreensão do outro (...) de forma a aprofundar o sentimento de responsabilidade social, ética e de cidadania (ET4);

(...) compromisso da instituição com a formação integral do ser humano, considerando aspectos relacionados ao mundo do trabalho e ao exercício da cidadania (ET5).

De acordo com o artigo 22 do texto da LDB (BRASIL, 1996), uma das finalidades da Educação Básica é que o educando tenha assegurada a formação comum indispensável para o exercício da cidadania, além do oferecimento de meios para progredir no trabalho e em estudos posteriores. No que se refere à educação profissional e tecnológica, o artigo 39 preconiza a sua integração aos diferentes níveis e modalidades de educação e às dimensóes do trabalho, da ciência e da tecnologia. Nesse sentido, importante destacar que nas Diretrizes Curriculares Nacionais para a Educação Profissional Técnica de Nível Médio (BRASIL, 2012), 
um dos princípios refere-se ao "trabalho assumido como princípio educativo, tendo sua integração com a ciência, a tecnologia e a cultura (...)".

Essas ideias são importantes na medida em que poderiam conduzir a educação profissional técnica de nível médio em direção a uma formação que extrapolasse o âmbito estritamente técnico, porém:

O ensino técnico é uma oferta educativa que representa, historicamente, no âmbito da educação, uma questão contraditória e com ambiguidades, entre a educação profissional e a educação propriamente dita (...) na sua relação com o ensino médio, dá-se uma disputa permanente entre orientaçóes profissionalizantes e/ou acadêmicas, entre objetivos propedêuticos e / ou econômicos (SIMÓES, 2010, p. 115).

$\mathrm{Na}$ concepção de educação tecnológica (não associada a qualquer nível ou modalidade, mas a uma dimensão essencial do processo educativo), entende-se a incorporação, na educação escolarizada, da integração entre ciência, tecnologia, cultura e trabalho (SIMÓES, 2010), o que encontra limites considerando a forma dual de organização do sistema educacional relacionada à manutenção da sociedade desigual no modo de produção capitalista.

Assim, de fato, ampliar a formação dos trabalhadores técnicos em saúde para além do eixo técnico - o que poderia sugerir os trechos mencionados anteriormente - é uma necessidade que exige compreensão alargada sobre a educação profissional e o enfrentamento inclusive, do predomínio da oferta de cursos subsequentes ao ensino médio na área da saúde, o que está estreitamente relacionado à privatização que é significativa nessa área, como já comentado.

Em relaçáo aos cursos analisados, a maioria é ofertada na modalidade subsequente, ou seja, após a finalização do ensino médio, possibilitando, dessa maneira, menores condições de articulaçôes entre formação geral e profissional.

Face ao não aprofundamento teórico em relação ao conceito de cidadania expresso nos planos, não é possível maiores análises, mas tomando o conjunto dos documentos, a partir de outros referenciais assumidos como o das competências, cabe refletir que a indicação de formação para a cidadania está mais dirigida para a constituição do "cidadão produtivo" que precisa se submeter às exigências do capital, em lógica que se aproxima da subordinação e náo da participação para o desenvolvimento de todas as suas potencialidades (FRIGOTTO; CIAVATTA, 2003). A concepção de cidadania coletiva, que considera o sujeito político, implica o resgate da individualidade como parte de um coletivo. Ideia essa distante da noçáo mercantil de cidadão produtivo que: 
"deve possuir as qualidades para a inserção em uma economia de mercado que o aliena de sua generalidade em comunhão política com os demais homens, para submetêlo aos ditames da produtividade exigida pela reprodução do capital” (FRIGOTTO; CIAVATTA, 2003, p. 57).

Há planos de curso que, nessa direção, também se referem, explicitamente, nos objetivos específicos, ao atendimento de uma demanda do mercado de trabalho ao:

Integrar o futuro técnico e auxiliar de enfermagem com o mercado de trabalho por meio da convivência com o meio profissional (ET1; ET2).

Outro plano analisado não faz referência explícita ao mercado quanto aos objetivos específicos, entretanto, ao longo do documento, apesar de apontar a necessidade da educaçáo geral, assume a importância que as demandas do mercado têm na proposição e desenvolvimento do curso:

(...) oferecimento de uma educação profissional (...) alicerçada na educação geral (...) assume também relevância a observância da demanda do mercado de trabalho e, em consequência, do nível de empregabilidade (...) (ET6).

Outros planos de curso indicam que:

Torna-se imprescindível que profissionais da área da Saúde divulguem informaçóes que promovam a melhoria da qualidade de vida (...) portanto o campo de trabalho do profissional (...) se amplia, ganhando projeção, em função da exigência que caracteriza o mercado (...). O desenvolvimento e o oferecimento de cursos técnicos em parceria com o setor produtivo/mercado de trabalho tem sido a principal diretriz do planejamento curricular da instituição (ET2);

A formação para a laboralidade está voltada para o desenvolvimento das competências profissionais, uma vez que o mundo do trabalho está se alterando contínua e profundamente, exigindo dos trabalhadores açōes que envolvam autonomia intelectual, pensamento críticoreflexivo, dinamismo e ética (ET3);

Constata-se uma grande demanda por técnicos que atendam às exigências do mercado e que correspondam ao perfil profissional exigido pelo processo de trabalho na área (ET4). 
Apreende-se, nesses documentos, que é feita menção a mudanças e a exigências do mercado que náo são claramente expressas, demandando determinadas açóes profissionais, na lógica das competências que será posteriormente enfocada neste texto. Assim, os dispositivos político-legais que estão na base dos documentos analisados e, em muitos momentos, neles citados fazem parte do ideário neoliberal, assim congruente ao cenário político da educação profissional desde os anos 1990, trazendo demandas para o campo da formação dos trabalhadores técnicos, na lógica de valorização do capital.

A partir dos anos 1990, a educação profissional brasileira passa por constantes reformulaçóes respaldadas nas novas exigências do mercado de trabalho, demandando flexibilidade e competências práticas. Nesse contexto, está em jogo uma dualidade de interesses entre a política de expansáo do capitalismo que almeja máo de obra habilitada, volumosa e de baixo custo e a política humanística, de valorizaçáo do ser humano que intenciona a formação integral (SOUZA; ALVES, 2011).

Cabe considerar também que, no conjunto dos documentos analisados, apreende-se um discurso híbrido relacionado às próprias legislaçóes. Por exemplo, a Resolução CNE/CEB no 06/2012 (BRASIL, 2012), apesar da fundamentação em preceitos neoliberais, também se refere a concepçóes do trabalho como princípio educativo, tendo sua integração com a ciência, tecnologia e cultura, politecnia, dentre outros, que se alicerçam em referencial teórico crítico.

Isso denota os embates entre grupos conservadores e progressistas que defenderam interesses diversos nos processos de construção da legislaçáo anteriormente mencionada: o primeiro na direção do fortalecimento do capital e o segundo na defesa da formação integral do trabalhador. Esses embates estão detalhados em alguns textos, como em Moura (2013) e Ramos (2016), sendo explicitadas contradiçóes que decorrem dos conflitos conceituais presentes no texto legal (MOURA, 2013).

No âmbito das escolas, em meio às diversas recontextualizaçóes que marcam a elaboração de um plano de curso, esse "hibridismo" conceitual, fruto dos embates políticos, também se faz presente e, provavelmente, tende ao distanciamento da formação humana, integral, na medida em que concepçóes distintas são mencionadas sem serem consideradas as tensóes presentes e as diferenças quanto às suas intencionalidades no processo formativo.

Segundo Saviani (2003), a perspectiva de formação humana implica ultrapassar a estratégia na sociedade capitalista de que o trabalhador tenha apenas conhecimentos o suficiente para ser eficiente no processo produtivo, sem ultrapassar este limite, a que se opóe a concepçáo de politecnia segundo Marx. Nessa direção, compreende Saviani (2003) que o processo de trabalho se desenvolva em uma unidade indissolúvel, uma vez que náo existe trabalho manual puro, tampouco trabalho intelectual puro. 
$\mathrm{Na}$ compreensão da politecnia, "cabe a possibilidade de uma plena e total manifestação de si mesmo independentemente das ocupaçóes específicas da pessoa" (MANACORDA, 2007, p. 48). A formação humana, nessa lógica, com enfoque tecnológico ou politécnico é uma

(...) exigência para a qualificação da força de trabalho para o processo social em todas as suas dimensóes, ao mesmo tempo pré-requisito do horizonte teórico e político dos processos de formação técnica e profissional mais específicos. (FRIGOTTO, 2010, p. 193)

Neste estudo, não será possível enfocar a compreensão dos processos de construção dos documentos institucionais dos cursos analisados pelos sujeitos envolvidos, bem como as repercussóes dos documentos nas práticas pedagógicas adotadas, que serão foco de outras pesquisas.

De qualquer modo, é possível afirmar que a tensão presente entre a formação para o mercado e a formação humana se reveste também de peculiaridades na área da saúde, na medida em que a formação dos trabalhadores envolve aproximaçóes ou afastamentos ao Sistema Único de Saúde (SUS), como política pública, que enfoca a saúde como direito do cidadáo e dever do Estado, na defesa de um projeto de sociedade que vai na contramáo do modelo privatista. Ou seja, as relações sociais de produção são geradoras da contradição entre saúde como direito ou como bem passível de troca no mercado e, somente na medida em que essa contradição for apreendida - tendo em vista o enfoque de transformação social -, a formação do trabalhador técnico da área da saúde poderá, de fato, assumir uma perspectiva de formação humana, integral.

Chama a atenção que, nos documentos das escolas técnicas que compóem este estudo, há dois planos de cursos de mesma área profissional - um de escola pública e o outro de escola privada - que não se referem à formação para o SUS. Há planos também de instituição pública que, nas partes introdutórias e nos objetivos, não fazem menção explícita à formação para o SUS, mas se reportam a açóes que se remetem à integralidade (um dos princípios do SUS). Todavia, não as contextualiza como açóes que implicam articulação na organização do sistema:

Formar técnicos (...) capazes de atuar como agentes na promoçáo da saúde, na prevenção das doenças e na recuperação dos que adoecem, visando à integralidade do ser humano (ET1; ET2);

Atuar como agente educativo na promoçáo e proteção da saúde e na prevençấo das doenças por meio de açôes educativas (...) (ET2). 
Há plano de curso de instituição privada que também não menciona nos objetivos do curso, de modo explícito, a formação para o SUS, muito embora faça menção a ações de promoção e de recuperação da saúde, assim como de prevenção de doenças nas partes introdutórias ou no perfil do profissional a ser formado:

Para atender às necessidades da população, as políticas públicas de saúde estão cada vez mais voltadas às ações de educação, promoção, prevenção e recuperação da saúde, o que contribui para a expansão da rede de atençáo, para a melhoria dos serviços de saúde (ET5);

É um profissional que precisa, além de conhecimentos técnico-científicos, de princípios que orientem as açôes de promoção da saúde e de responsabilidade social e ambiental, de forma a contribuir para o bem-estar e a saúde da populaçáo (ET5).

Outros planos, tanto de instituição pública como privada, explicitam a formação voltada para o SUS nos objetivos do curso ou em "objetivos de aprendizagem" e, também, preconizam ações de promoção à saúde, de prevenção de agravos e recuperação, bem como o atendimento às necessidades de saúde:

Formar profissionais de saúde (...) como atores importantes no desenvolvimento e implantação do SUS (ET3);

Adequar às exigências legais, às especificidades dos serviços do SUS e à realidade dos trabalhadores da saúde (ET3);

As atividades desenvolvidas pelo Técnico (...) devem estar em consonância com os princípios do SUS (ET3);

Formar técnico de nível médio para atuar em laboratório (...) na perspectiva da promoção da saúde, prevenção de agravos e tratamento de doenças (ET4).

Desenvolver um processo educativo com uma visão crítica e científica da realidade de saúde na comunidade situando os problemas no contexto sociopolítico e cultural, compreendendo suas causas e atuando como agentes de mudança, comprometido com as necessidades da populaçáo (ET6);

Atuar nos diferentes contextos profissionais (...) respeitando os princípios do Sistema Único de Saúde (Universalidade, Equidade e Integralidade) (ET6).

Alguns planos, fundamentados em documentos citados anteriormente, trazem uma contextualização acerca do cenário da saúde no Brasil, apontando também olhares híbridos. Dessa forma, são neles apontadas a necessidade de formação 
profissional que favoreça o cuidado integral em saúde, envolvendo ampliação dos espaços profissionais (em contraposição ao paradigma hospitalocêntrico e ao predomínio do saber clínico), assim como a intersetorialidade e a compreensão, pelo trabalhador, das bases sociais, econômicas, técnicas e científicas do seu trabalho. Todavia, o SUS, como política pública calcada no direito à saúde, não é explicitamente pontuado e explorado nos documentos, uma vez que a lógica de focar a área da saúde como amplo mercado que vem sendo modificado que demanda adaptaçôes é claramente indicada (ET1, ET2, ET5 e ET6).

As Escolas Técnicas do SUS (ETSUS) não se encontram nessa situação, pois os objetivos dos cursos estáo vinculados explicitamente à formação para o SUS. $\mathrm{E}$, apesar de não serem feitas consideraçóes aprofundadas sobre os conceitos do campo da saúde que alicerçam o projeto de formação (semelhante ao que acontece nos documentos das demais escolas), preserva-se, ao longo dos planos, coerência mais estreita da relação entre a formação e o SUS como política pública.

Nessa direção, por exemplo, um dos objetivos de determinado curso de uma ETSUS tem como finalidade:

Formar profissionais de nível médio em Enfermagem com visão crítica da realidade, contextualizando os problemas locorregionais, considerada a estrutura social, política, cultural e econômica do Município, do Estado e do país, com vistas à promoção da qualidade no atendimento (ET3).

Esses objetivos que enfocam a necessidade da visão crítica da realidade com a intenção de que os problemas locorregioanais de saúde sejam contextualizados, nas relaçóes com a estrutura social, política, cultural e econômica, terão maiores condiçôes de serem viabilizados na medida em que alguns critérios importantes para o funcionamento dessas escolas, específicas para a formação do trabalhador da área da saúde, incluem a sua vinculação à gestão do SUS, por meio de vínculo direto com Secretaria Estadual ou Municipal de Saúde ou cogestão, tendo como foco a formação dos trabalhadores para o SUS (BRASIL, 2009).

Pesquisa que se voltou a explorar as concepçóes político-pedagógicas de gestores e a analisar projetos pedagógicos de cinco escolas técnicas do SUS de todas as regiôes do Brasil (GALVÁO; SOUSA, 2012) aponta que esses profissionais náo se restringem à dimensão técnica, sobressaindo-se dessa forma a dimensão política, tendo em vista a articulação das ETSUS com as instâncias decisórias da área da saúde, como a Comissão Intergestora Bipartite, as Comissóes de Integração EnsinoServiço, Secretarias Municipais e Estaduais de Saúde, sendo os princípios do SUS norteadores dos planos de cursos. Entretanto, apesar disso, outra pesquisa também realizada com ETSUS aponta que não foi apreendida, na maioria das entrevistas feitas com coordenadores pedagógicos, uma associação entre 
(...) a natureza econômico-social e a política do SUS e tais determinaçóes na relação entre trabalho e educação do técnico em saúde. Se esta consciência existe, não se pode vê-la como fundamento explícito de uma concepçáo epistemológica, ético-política e pedagógica das escolas (...) (RAMOS, 2009, p. 164-165).

Essa constatação é muito significativa e pode ter relações com as ambiguidades conceituais presentes nos planos de cursos dessas escolas, contextualizadas no cenário das políticas neoliberais, o que poderá ser melhor explicitado em relação à adoção do referencial das competências a seguir explorado.

Nos documentos analisados, é mencionado que a formação será desenvolvida a partir de competências. Esse foco é comum a todos os planos, tendo em vista que esse referencial está presente nos dispositivos político-legais da educação profissional técnica de nível médio, inclusive na área da saúde. A seguir, destacamse recortes de alguns documentos:

O currículo (...) a partir de competências será direcionado para a construçáo da aprendizagem do aluno enquanto sujeito do seu próprio desenvolvimento. Para tanto, a organização do processo de aprendizagem privilegiará a definição de objetivos de aprendizagem e/ou questôes geradoras que orientam e estimulam a investigaçáo, o pensamento e as açôes, assim como a soluçáo de problemas (ET1; ET2);

(...) é necessário adotar um parâmetro para desenvolvimento de competências, pois está sendo exigida (da pessoa integral) a capacidade de aprendizado e mudança contínuos, traduzidos em parte na capacidade de adaptação, pois as necessidades mudam constantemente, com as transformaçôes técnicas e científicas, mas também com as alteraçôes sociais e culturais (ET1; ET2);

(...) cada área é composta por um conjunto de unidades estruturadas a partir das competências específicas, trabalhadas nas metodologias ativas, e estas seráo desenvolvidas em momentos de aulas teórico-práticas e de práticas profissionais (ET3);

(...)Tal conjunto de saberes agrega conteúdos e açóes de natureza distintas, porém, indissociáveis, que se articulam e se efetivam em habilidades, conhecimentos, atitudes e valores, conformando, assim, as competências pertinentes e necessárias ao trabalho do técnico (...) (ET4);

As orientaçôes metodológicas (...) pautam-se pelo princípio 
da aprendizagem com autonomia e pela metodologia de desenvolvimento de competências, estas entendidas como ação/fazer profissional observável, potencialmente criativo, que articula conhecimentos, habilidades e atitudes/valores e que permite desenvolvimento contínuo (ET5);

(...) a formação profissional por competências requer uma pedagogia que focalize metodologias dinâmicas centradas no aprendiz, enquanto agente de seu processo formativo, o que implica, necessariamente, incluir variadas atividades e recursos didáticos (...) (ET6);

Garantir o desenvolvimento de competências técnica, política e humana dos trabalhadores, no que se refere ao domínio de conhecimentos, atitudes ético-profissionais e habilidades técnicas inerentes à atuação profissional (...) (ET3).

O referencial das competências está relacionado à capacidade de mobilizar, articular e pôr em ação valores, conhecimentos e habilidades para o desempenho eficiente e eficaz das atividades (BRASIL, 1999; BRASIL, 2012). Diante dessa perspectiva, verifica-se uma intenção de adequação da educação à esfera produtiva.

Esse referencial aponta assim para uma concepção segundo a qual a educação é instrumento que formará o indivíduo na medida necessária para sua inserção na "nova sociedade" marcada pela aproximação da escola à empresa, com mudanças nas relaçóes de trabalho que responsabilizam o indivíduo trabalhador pelo desenvolvimento de suas potencialidades e empregabilidade, todavia, sem condiçóes de assegurá-la. Dessa maneira, configura-se presente a lógica de desresponsabilização do Estado (OLIVEIRA, 2003; FIDALGO; FIDALGO, 2007) e apreende-se, pois, a intencionalidade da formação de mão de obra em contraposição à formação humana.

Ramos (2002, p. 413), sinaliza que os conteúdos disciplinares passam a ser insumos para desenvolvimento de competências e são denominados como "bases tecnológicas" decorrentes de princípios e conceitos científicos em uma relação linear, em uma concepção (neo)pragmática de conhecimento que subordina conceitos aos limites de sua instrumentalidade ou das formulaçóes espontâneas. "Se em relação ao conhecimento se dissolvem as fronteiras entre conceito científico e conceito cotidiano, em relação às aprendizagens prevalece o senso comum ou o condutivismo", sendo dessa forma as competências reduzidas ao procedimento.

Ciavatta e Ramos (2012) entendem, a partir da lógica de competências assumida nas DCNs da Educação Profissional Técnica de Nível Médio, que o foco reside nos comportamentos e na metodologia, valorizando assim sobremaneira a experiência dos alunos. As autoras ainda consideram as experiências apenas como primeiro passo do "método histórico" que envolve: 
(...) partir do concreto empírico, analisá-lo, buscando as mediaçốes contraditórias, e ordená-las no plano do pensamento como forma de apreendê-la concreta e criticamente para além da experiência sensível (...) (CIAVATTA; RAMOS, 2012, p. 24).

As mesmas autoras explicitam que se o conhecimento científico for tomado apenas como recurso para desenvolver competências, a valorização da experiência do aluno pode conduzir à reificação do saber prático em detrimento da compreensão dos fundamentos e dos próprios limites e pertinência desse saber.

Ramos (2002), pontua que é possível que os processos de aquisição de saberes possam ser organizados em torno de atividades profissionais. No entanto, é fundamental que se distingam os saberes teóricos e conceitos científicos que são independentes das açôes e os saberes práticos que permanecem imanentes à ação que intervêm. Assim, a abordagem pedagógica de atividades profissionais competências - pode considerá-las como códigos que apoiem os professores, em suas disciplinas, considerando objetivos e projetos comuns, não determinando, contudo, que tais açóes sejam os únicos pontos de partida.

Convém ressaltar que, por exemplo, nos documentos dos cursos da ET3, há uma referência a uma competência humana que comporta, dentre outras, uma dimensão sociopolítica que se articula ao cuidar em saúde, o que merece ser melhor explorado. São necessários, pois, outros estudos que permitam aprofundar as compreensões sobre as concepçôes e as práticas no que se refere à implementação do referencial de competências nessas escolas técnicas, tendo como suporte os estudos teóricos que associam esse referencial às fundamentaçóes de base funcionalista e pragmática e, portanto, em contraposição à perspectiva de formação humana considerada neste artigo, coerente à formação dos trabalhadores técnicos da saúde.

\section{Considerações Finais}

Os documentos dos cursos técnicos analisados neste estudo, contextualizados no cenário político neoliberal, permitem visualizar a tensão presente entre a formação para o mercado e a formação humana como concepçóes que trazem implicaçôes diversas em termos da formação da classe trabalhadora e da formação no campo da saúde.

Os movimentos de aproximação e afastamento ao projeto de formação para o SUS são diversos, indo desde a não mençáo à intencionalidade de formação para o SUS até a menção dessa intenção, sendo interessante que não há uma diferenciação rígida quanto ao caráter público ou privado das escolas quanto a tais movimentos. Ou seja, há curso tanto de instituição pública 
como privada que sequer cita o SUS no seu projeto de formação, ao passo que há cursos que fazem algumas relaçóes entre formação e SUS, tanto na rede pública como privada. Os documentos das ETSUS guardam uma relação mais estreita nessa direção.

Todavia, os documentos não tecem consideraçóes que permitam apreender aproximaçóes ao entendimento de que as relaçóes sociais de produção são geradoras da contradição entre saúde como direito ou como bem passível de troca no mercado e, somente na medida em que essa contradiçáo for apreendida tendo em vista o enfoque de transformação social - a formação do trabalhador técnico da área da saúde poderá, de fato, assumir uma perspectiva de formaçáo humana, integral. Essa ideia se fortalece na medida em que todos os documentos analisados incorporam o referencial das competências conforme indicam os dispositivos legais, o que traz forte associação com os ditames neoliberais.

Nesse cenário, há mais afastamentos que aproximaçōes à formação humana na lógica apontada neste texto. Contudo, contraditoriamente, é a partir desse referencial de formação que é possível, ao trabalhador, realizar leitura crítica das relaçóes sociais no modo de produção capitalista, reconhecendo-se não como indivíduo isolado que precisa buscar meios de sobrevivência, mas como pertencente a uma classe social e que tem a possibilidade de questionar o status quo e lutar por transformação social. Essa perspectiva é coerente à formação compromissada com o SUS e com as necessidades de saúde.

\section{Referências}

BRASIL. Lei no 9.394, de 20 de dezembro de 1996. Estabelece as diretrizes e bases da educação nacional. Brasília: 1996. Disponível em: http://portal.mec.gov. br/seed/arquivos/pdf/tvescola/leis/lein9394.pdf. Acesso em: 11 nov. 2020.

BRASIL. Decreto no 2.208 de 17 de abril de 1997. Regulamenta o $\$ 2$ o do decreto 36 e os artigos 39 a 42 da Lei 9.394, de 20 de dezembro de 1996, que estabelece as diretrizes e bases da educação nacional. Brasília: 1997. Disponível em: http://www.planalto.gov.br/ccivil_03/decreto/D2208.htm. Acesso em: 10 nov.2020.

BRASIL. Ministério da Educação. Conselho Nacional de Educação. Câmara de Educação Básica Resolução CNE/CEB no 04/99. Institui as Diretrizes Curriculares Nacionais para a Educação Profissional de Nível Técnico. 1999. Disponível em: http://portal.mec.gov.br/setec/arquivos/pdf/RCNE_CEB04_99. pdf. Acesso em: 21 dez. 2020. 
BRASIL. Ministério da Educação. Educação Profissional. Referenciais Curriculares Nacionais da Educaçáo Profissional de Nível Técnico. Brasília: 2000. Disponível em: http://portal.mec.gov.br/setec/arquivos/pdf/introduc.pdf. Acesso em: 21 dez. 2020.

BRASIL. Ministério do Trabalho e Emprego. Classificação Brasileira de Ocupaçóes - CBO 2002. Brasília: 2002. Disponível em: https://www.camara. leg.br/proposicoesWeb/prop_mostrarintegra;jsessionid=0B39D1C37DB86983 44DE88D500EF8E3B . proposicoes Web2 codteor=382544\&filename=Legislaca oCitada+-INC+8189/2006. Acesso em: 21 dez. 2020.

BRASIL. Decreto no 5.154, de 23 de julho de 2004. Regulamenta o $\$ 2^{\circ}$ do art. 36 e os arts. 39 a 41 da Lei no 9.394, de 20 de dezembro de 1996, que estabelece as diretrizes e bases da educação nacional, e dá outras providências. Brasília: 2004. Disponível em: http://www.planalto.gov.br/ccivil_03/_ato2004-2006/2004/ decreto/d5154.htm. Acesso em: 10 nov. 2020.

BRASIL. Ministério da Saúde. Portaria no 2.970, de 25 de novembro de 2009 que Institui a Rede de Escolas Técnicas do SUS e dispóe sobre as diretrizes para a sua organização. Ministério da Saúde, 2009. Disponível em: http://bvsms.saude. gov.br/bvs/saudelegis/gm/2009/prt2970_25_11_2009_rep.html. Acesso em: 21 dez. 2020.

BRASIL. Ministério da Educação. Resoluçáo no 06, 20 de setembro de 2012. Define diretrizes curriculares nacionais para a educaçáo profissional técnica de nível médio. Brasília: 2012. Disponível em: http://portal.mec.gov.br/index. php?option=com_content\&view=article\&id=17417\&Itemid=866. Acesso em: 6 set. 2020.

BRASIL. Instituto Nacional de Estudos e Pesquisas Educacionais Anísio Teixeira. Censo Escolar da Educaçáo Básica 2013: resumo técnico. Brasília: $2014 a$. Disponível em: http://download.inep.gov.br/educacao_basica/censo_escolar/ resumos_tecnicos/resumo_tecnico_censo_educacao_basica_2013.pdf. Acesso em: 18 dez. 2020.

BRASIL. Ministério da Educação. Catálogo Nacional dos Cursos Técnicos. Brasília: 2014b. Disponível em: http://sistemas.wiki.ifpr.edu.br/lib/exe/fetch. php?media=catalogo_2014.pdf. Acesso em: 20 ago. 2020.

BRASIL. Conselho Nacional de Saúde. Resoluçáo no 510, de 7 de abril de 2016. Dispóe sobre as normas aplicáveis a pesquisas em Ciências Humanas e Sociais. Diário Oficial da União. Brasília, n. 98, p. 44-6, 24 maio 2016, Seção 1. Disponível em: http://www.conselho.saude.gov.br/resolucoes/2016/Reso510. pdf. Acesso em: 21 dez. 2020. 
BRASIL. Ministério da Educação. Conselho Nacional de Educação. Parecer CNE/CP no: 7/2020, 19 de maio de 2020. Define Diretrizes Curriculares Nacionais para a Educação Profissional e Tecnológica, a partir da Lei $\mathrm{n}^{\circ}$ 11.741/2008, que deu nova redaçáo à Lei de Diretrizes e Bases da Educaçáo Nacional (LDB). Disponível em: http://portal.mec.gov.br/docman/julho-2020pdf/151591-pcp007-20/file. Acesso em 1 nov. 2020.

CAIRES, V. G.; OLIVEIRA, M. A. M. Educação profissional brasileira: da Colônia ao PNE 2014-2024. Petrópolis: Vozes, 2016.

CAMPOS, G. W. S. et al. Direito à saúde: o Sistema Único de Saúde está em risco? Interface - Comunicaçáo, saúde, educaçáo, Botucatu, v. 20, n.56, p. 261-266, mar. 2016. Disponível em: http://www.scielo.br/scielo.php?script=sci_arttext\&pid=S1414$32832016000100261 \& \operatorname{lng}=$ pt\&nrm=iso. Acesso em: 21 dez. 2020.

CELlARD, A. A análise documental. In: POUPART, J. et al. A pesquisa qualitativa: enfoques epistemológicos e metodológicos. Rio de Janeiro: Vozes, 2012. p. 295-316.

CIAVATTA, M.; RAMOS, M. A "era das diretrizes": a disputa pelo projeto de educação dos mais pobres. Revista Brasileira de Educaçáo, Rio de Janeiro, v. 17, n. 49, p. 11-37, jan./abr. 2012. Disponível em: http://www.scielo.br/scielo. php?script=sci_arttext \&pid=S1413-24782012000100002\&lng=en\&nrm=iso. Acesso em: $21 \mathrm{dez} .2020$.

FIDALGO, N. R. L.; FIDALGO, F. Refluxos sociais da lógica de competências: o processo de individualização em foco. In: FIDALGO, F.; OLIVEIRA, M. A. M.; FIDALGO, N. L. R. Educaçáo profissional e a lógica das competências. Petrópolis: Vozes, 2007. p. 17-70.

FRIGOTTO, G. Educaçáo e a crise do capitalismo real. 6.ed. São Paulo: Cortez, 2010.

FRIGOTTO, G.; CIAVATTA, M. Educar o trabalhador cidadão produtivo ou o ser humano emancipado? Trabalho, Educaçáo e Saúde, Rio de Janeiro, v.1, n.1, p. 45-60, 2003. Disponível em: http://www.scielo.br/scielo.php?script=sci_arttext\&pid=S1981$77462003000100005 \& \operatorname{lng}=$ en\&nrm=iso. Acesso em: 21 dez. 2020.

GALVÃO, E. A.; SOUZA, M. F. As escolas técnicas do SUS: que projetos político-pedagógicos as sustentam? Revista de Saúde Coletiva, Rio de Janeiro, v. 22, n. 3, p. 1159-1189, 2012. Disponível em: https://www.scielosp.org/article/ physis/2012.v22n3/1159-1189/. Acesso em: 21 dez. 2020.

GAMBOA, S. S. Pesquisa em educaçáo: métodos e epistemologias. 2. ed. Chapecó: Argos, 2012. 
GHEDIN, E.; FRANCO, M. A. S. Questóes de método na construçáo da pesquisa em educaçáo. 2. ed. São Paulo: Cortez, 2011.

KOSIK, K. Dialética do concreto. 2. ed. Rio de Janeiro: Paz e Terra, 1976.

KUENZER, A. Z. Trabalho e escola: a flexibilização do ensino médio no contexto do regime de acumulação flexível. Educação e Sociedade. Campinas, v. 38, n. 139, p. 331-354, abr./jun. 2017. Disponível em: https:/www.scielo.br/pdf/es/ v38n139/1678-4626-es-38-139-00331.pdf. Acesso em: 21 dez. 2020.

MANACORDA, M. A. Marx e a pedagogia moderna. Campinas: Alínea, 2007. MOROSINI, M. V. G. C. et al. Trabalhadores técnicos em saúde: aspectos da qualificação profissional no SUS. Rio de Janeiro: Escola Politécnica de Saúde Joaquim Venâncio, 2013.

MOURA, D. H. Ensino médio e educação profissional: dualidade histórica e possibilidades de integração. In: MOLL, J. Educação profissional e tecnológica no Brasil contemporâneo: desafios, tensôes e possibilidades. Porto Alegre: Artmed, 2010. p. 58-79.

MOURA, D. H. Ensino médio e educação profissional no Brasil nos anos 2000: movimentos contraditórios. In: MOURA, D. H. Produçáo de conhecimento, políticas públicas e formação docente em educaçáo profissional. Campinas: Mercado de Letras, 2013. p.141-200.

MOURA, D. H.; LIMA FILHO, D. L. A reforma do ensino médio: regressão de direitos sociais. Revista Retratos da Escola, Brasília, v. 11, n. 20, p. 109-129, jan./ jun. 2017. Disponível em: http//www.esforce.org.br. Acesso em: 21 dez. 2020.

OLIVEIRA, R. A (des) qualificação da educaçáo profissional brasileira. São Paulo: Cortez, 2003.

OLIVEIRA, R. A reforma da educação profissional nos anos 90. In: BATISTA, E. L.; MÜLLER, M. T. A educaçáo profissional no Brasil: história, desafios e perspectivas para o século XXI. Campinas: Alínea, 2013. p. 219-234.

PRONKO, M. A. (Org.) A formação de trabalhadores técnicos em saúde no Brasil e no Mercosul. Rio de Janeiro: Fiocruz/EPSJV, 2011. Disponível em: https://www.arca.fiocruz.br/handle/icict/26282. Acesso em: 15 de dez. 2020.

RAMOS, M. Concepçóes e práticas pedagógicas nas escolas técnicas do Sistema Único de Saúde: fundamentos e contradições. Trabalho, Educação e Saúde, Rio de Janeiro, v. 7, (supl.) 1, p. 153-173, 2009. Disponível em: http://www.scielo. $\mathrm{br} /$ scielo.php?script=sci_arttext\&pid=S1981-77462009000400008\&lng=en\&n $\mathrm{rm}=\mathrm{iso} \& \mathrm{t} \operatorname{lng}=\mathrm{pt}$. Acesso em: 15 de ago. 2020. 
RAMOS, M. N. A educação profissional pela pedagogia das competências e a superfície dos documentos oficiais. Educaçáo e Sociedade, Campinas, v. 23, n. 80, p. 401-422, set. 2002. Disponível em: https://www.scielo.br/pdf/es/ v23n80/12939.pdf. Acesso em: 21 dez. 2020.

RAMOS, M. N. O currículo na perspectiva de classe: desafios e possibilidades para a educação profissional. X Seminário Nacional do HISTEDBR, 18 a 21 julho 2016, UNICAMP, Campinas, 2016. Disponível em: 943-2718-1-pb.pdf (unicamp.br). Acesso em: 21 dez. 2020.

ROMANELLI, O. O. História da educação no Brasil (1930-1973). 38. ed. Petrópolis: Vozes, 2012.

RAMOS, M. N. Ensino Médio Integrado: lutas históricas e resistências em tempos de regressão. Educaçáo Profissional e Tecnológica em Revista, Vitória, v. 1, nº 1, 2017. Disponível em: https://ojs.ifes.edu.br/index.php/ept/article/ view/356/317. Acesso em: 21 dez. 2020.

SAVIANI, D. O choque teórico da politécnica. Trabalho, Educação e Saúde, Rio de Janeiro, v. 1, n. 1, p. 131-152, 2003. Disponível em: http://www.scielo. $\mathrm{br} /$ scielo.php?script $=$ sci_arttext\&pid=S1981-77462003000100010\&lng=en\&n rm=iso. Acesso em: 21 dez. 2020.

SIMÓES, C. A. Educação técnica e escolarização de jovens trabalhadores. In: MOLL, J. (Org.). Educaçáo profissional e tecnológica no Brasil contemporâneo: desafios, tensóes e possibilidades. Porto Alegre: Artmed, 2010. p. 96-119.

SOUZA, J. C. M.; ALVES, M. F. Atualização das diretrizes curriculares para educação profissional técnica de nível médio: tensóes entre público e privado. In: MACHADO, M. M.; RODRIGUES, M. E. C. Educaçáo dos trabalhadores: políticas e projetos em disputas. Campinas: Mercado de Letras, 2011. p. 299-326.

SOUZA, L. E. P. F. et al. Os desafios atuais da luta pelo direito universal à saúde no Brasil. Ciência \& Saúde Coletiva, Rio de Janeiro, v. 24, n. 8, p. 27832792, ago. 2019. Disponível em: http://www.scielo.br/scielo.php?script=sci_ arttext\&pid=S1413-81232019000802783\&lng=pt\&nrm=iso. acessos em: 21 dez. 2020. 